\title{
Descarte inadequado de resíduos da construção civil na área urbana do município de Campina Grande - PB
}

\section{Inadequate disposal of construction waste in the urban area of the city of Campina Grande - PB}

Data de entrada: $11 / 07 / 2019$

Data de aprovação: 26/09/2019

Raphael Almeida de Limaa"* | William de Paiva' | Laércio Leal' | Daniel Epifânio Bezerra' | Yago Rocha de Souza ${ }^{1}$

DOI: https://doi.org/10.36659/dae.2020.084

ORCID ID

Lima RA (iD https://orcid.org/0000-0002-5262-5921

Paiva W (ID) https://orcid.org/0000-0003-0220-1247
Leal L (D) https://orcid.org/0000-0002-8175-4378

Bezerra DE (D) https://orcid.org/0000-0002-2788-872X

Souza YR (D) https://orcid.org/0000-0001-9401-4822

\section{Resumo}

O descarte inadequado de resíduos da construção civil (RCC) em locais públicos tem provocado diversos problemas de saneamento ambiental nos municípios brasileiros, principalmente naqueles onde a população urbana é mais concentrada. Diante disso, o objetivo deste trabalho é investigar os principais locais de descarte de RCC espaIhados pela área urbana do município de Campina Grande, Paraíba, por meio do Sistema de Informação Geográfica (SIG). $O$ procedimento metodológico utilizado teve como base o software Google Earth Pro, que fornece a série temporal de imagens da região. As informações compreendem o período entre maio de 2018 e maio de 2019. Nesse período, foram identificados e comprovados 45 locais de descarte inadequado de RCC. Por meio dos resultados obtidos, constata-se que o descarte inadequado de RCC produz um passivo ambiental no tocante a água, solo e ar, bem como abriga vetores de doença, além de atrair o descarte de resíduo sólido urbano (RSU) para o local. Palavras-chave: Resíduo da Construção Civil. Sistema de Informação Geográfica. Descarte inadequado. Saneamento Ambiental. Passivo ambiental.

\section{Abstract}

The inadequate disposal of construction waste (CW) in public places has caused several problems of environmental sanitation to Brazilian municipalities, especially those where the urban population is denser. Therefore, the objective of this work is to analyze the main disposal sites of RCC scattered throughout the urban area of the city of Campina Grande, Paraiba, through the Geographic Information System (GIS). The methodological procedure used was based on the software Google Earth Pro, that provides the temporal series of images of the region. The information covers the period between May 2018 and May 2019. During this period, 45 sites of inappropriate RCC disposal were identified and proven. Through the results obtained, it is verified that the inappropriate disposal of RCC produces an environmental liability in relation to water, soil and air, as well as, they harbor disease vectors, in addition to attracting urban solid waste (USW) to the site.

Keywords: Construction waste. Geographic Information System. Inappropriate disposal. Environmental sanitation. Environmental liability.

\footnotetext{
${ }^{1}$ Universidade Estadual da Paraíba - Campina Grande - Paraíba - Brasil.

* Autor correspondente: raphael.alahotmail.com.
} 


\section{INTRODUÇÃO}

O rápido crescimento demográfico e, por conseguinte, o aumento das atividades do setor construtivo, foi essencial para a urbanização das principais cidades. Com o tempo, a larga exploração dos recursos naturais e o desperdício nas obras de construções, reformas e demolições elevaram a geração de RCC a índices alarmantes (HALMEMAN, 2010).

De acordo com a Associação Brasileira de Limpeza Pública e Resíduos Especiais (ABRELPE), em 2017 os municípios recolheram cerca de 45 milhões de toneladas de resíduos da construção civil (RCC), diminuindo cerca de 0,08\% em comparação com o ano de 2016. Porém, por não levar em consideração os construtores informais que realizam pequenas obras e reformas como pessoa física, esse panorama necessita de uma atenção especial, pois estima-se que a produção de RCC no Brasil é de mais de 84 milhões de toneladas por ano (BRASIL, 2010; CONTRERAS et al., 2016; ABRECON, 2015).

Entre os serviços de construção, reforma e demolição, os de reforma e demolição contribuem com $60 \%$ do total de RCC produzido, enquanto o processo construtivo participa com $40 \%$. Apesar do grande volume gerado, a deficiência na gestão dos RCC e a falta de fiscalização têm constribuido para o descarte inadequado de RCC em áreas públicas, sítios e logradouros, prejudicando o saneamento ambiental das cidades (FAVARETTO et al., 2017).

Por meio da resolução do Conselho Nacional do Meio Ambiente (Conama) n. 307/2002 e suas alterações, buscou-se minimizar a problemática dos resíduos oriundos do processo de construção, demolição e reformas. Dessa forma, foram determinadas diretrizes, critérios e procedimentos para a gestão adequada do RCC (BRASIL, 2002). Entretanto, no contexto atual, existem poucos munícipios que gerenciam corretamen- te os RCC ou que possuam o seu Plano Municipal de Gestão de Resíduos da Construção Civil (PMGRCC).

Sabendo da importância da gestão dos resíduos, e tendo em vista a nova temática do desenvolvimento sustentável, surge a necessidade de identificar a poluição difusa provocada pelo descarte inadequado de RCC. Diferentemente da poluição pontual, que se caracteriza por uma ação modificadora localizada, entende-se por poluição difusa as fontes de contaminação que se distribuem aleatoriamente em um sistema, não se concentrando em um único local (PRODANOFF, 2005).

Persistir no hábito de descartar inadequadamente o RCC traz consigo diversos impactos nocivos ao ecossistema, estimula a proliferação de vetores e prejudica a infraestrutura da cidade e a drenagem natural do ecossistema, além da transição de veículos e pessoas (KLEIN, 2017).

Com a gestão eficiente e uma fiscalização atuante, é possível minimizar a quantidade de áreas de acúmulo de RCC. Diante disso, este trabalho teve como objetivo investigar os principais locais de descarte inadequado de RCC utilizando o Sistema de Informação Geográfica (SIG) e visitas in loco na área urbana do município de Campina Grande, Paraíba.

\section{METODOLOGIA}

A metodologia deste trabalho foi dividida em três etapas. A primeira etapa envolve a busca por locais de acúmulo de RCC na área urbana do município de Campina Grande - PB por meio do software Google Earth Pro. A segunda etapa refere-se à visita nos locais identificados e aos registros fotográficos dos volumes de RCC que são descartados aleatoriamente pela zona urbana. A terceira etapa trata da delimitação da área e o georreferenciamento do local onde existe a presença de descarte de RCC. 


\subsection{Caracterização da área de estudo}

O local de referência para essa pesquisa experimental foi a área urbana do município de Campina Grande - PB (Fig. 1). A cidade possui aproximadamente 407 mil habitantes, e a economia se divide em atividades industriais, construção civil, comércio varejista e atacadista, extração mineral, pecuária e agricultura. A cidade possui 50 bairros e localiza-se no planalto da Borborema, no estado da Paraíba (IBGE, 2018).

Figura 1 - Localização do município de Campina Grande - PB



\subsection{Locais de descarte de RCC}

O período referente à pesquisa foi de maio de 2018 até maio de 2019, onde foi realizada a identificação dos principais locais de descarte inadequado de resíduos oriundos da construção civil por meio do software livre Google Earth Pro. Por meio da comparação da série histórica de imagens dos anos anteriores, conforme exemplo nas Fig. 2 a 4, foram identificados os locais plausíveis de descarte inadequado de RCC.

As imagens escolhidas são as que possuem a melhor visualização, caracterizando-se como isentas de sombras, o que permitiu identificar melhor os locais de descarte de RCC. 
Figura 2 - Série histórica de imagens (Bairro Bela Vista)

(A) setembro de 2017

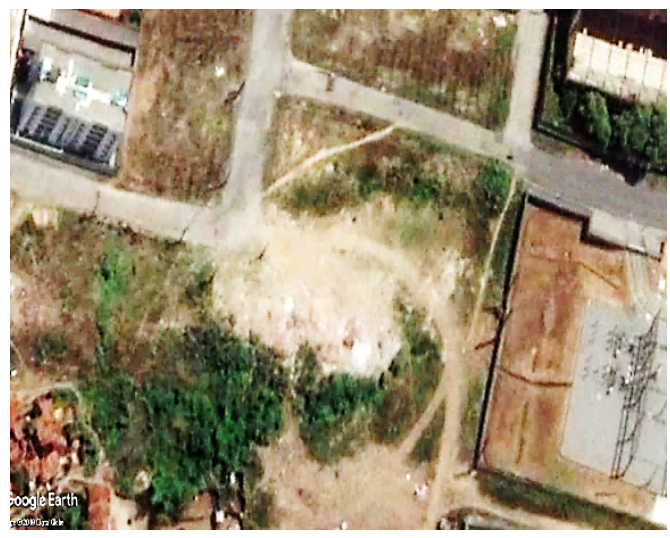

(B) dezembro de 2018



Fonte: Google Earth Pro (2019)

Figura 3 - Série histórica de imagens (Bairro TamboR)

(A) setembro de 2018

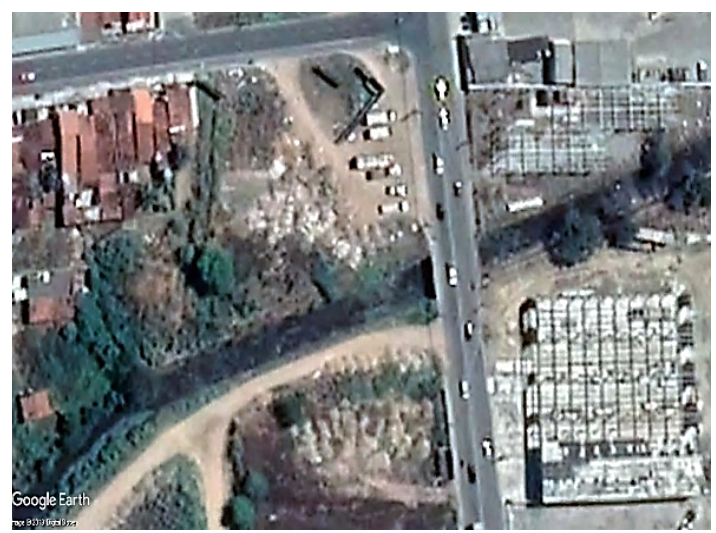

(B) maio de 2019

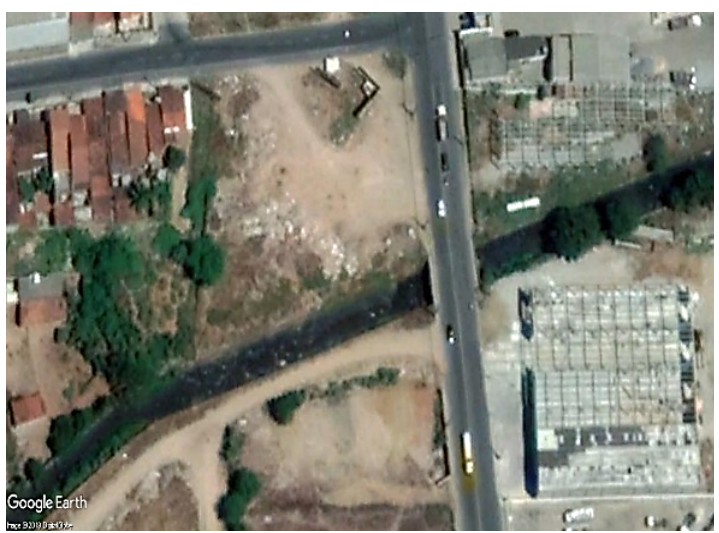

Fonte: Google Earth Pro (2019)

Figura 4 - Série histórica de imagens (Bairro Monte Castelo)

(A) dezembro de 2017

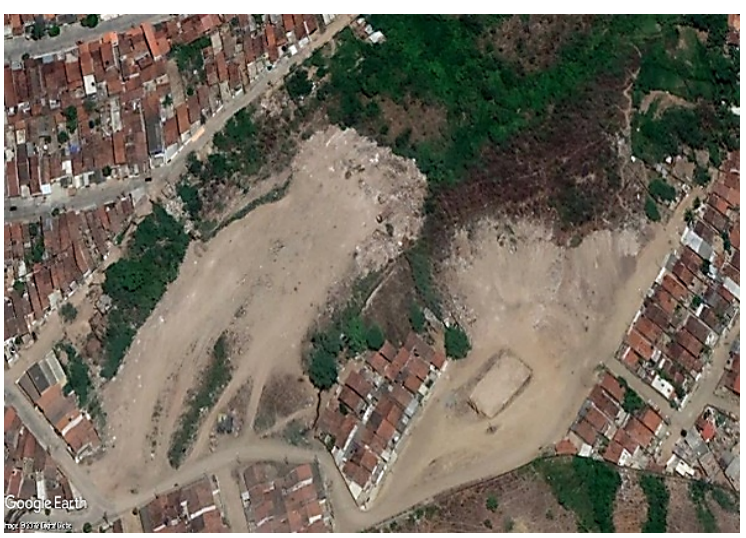

(B) setembro de 2018

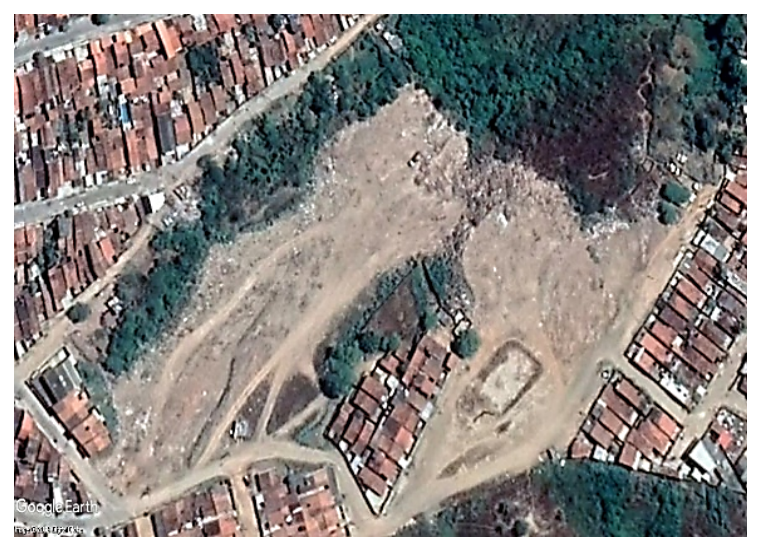

Fonte: Google Earth Pro (2019) 


\subsection{Visita nos locais de descarte}

Com a identificação dos locais de descarte, foi realizada a visita in loco para comprovar a presença de RCC no local. Essa visita é indispensável, uma vez que o software fornece imagens atualizadas na vertical, mas não em tempo real. As imagens na horizontal disponíveis pelo Google Street View estão desatualizadas e são úteis apenas como um indicador.

\section{RESULTADOS E DISCUSSÕES}

Após o levantamento, foram comprovados 45 locais de descarte inadequado de RCC espaIhados pela cidade de Campina Grande. Inicialmente são apresentados os resultados referentes à zona da cidade em que se encontra - local de descarte, o identificador (Id) para visualização no mapa, o bairro, a localização geográfica dos pontos identificados e a área do local, conforme a Tabela 1.

Tabela 1 - Locais de descarte de RCC

\begin{tabular}{|c|c|c|c|c|c|c|}
\hline $\mathrm{N}^{\circ}$ & Zona da Cidade & Id. & Bairro & Latitude & Longitude & Área $\left(\mathrm{m}^{2}\right)$ \\
\hline 1 & \multirow{9}{*}{ Zona Norte } & 1 & Alto Branco & $7^{\circ} 11^{\prime} 54.38^{\prime \prime S}$ & $35^{\circ} 52^{\prime} 43.59^{\prime \prime} \mathrm{O}$ & 1.154 \\
\hline 2 & & 2 & Alto Branco & $7^{\circ} 12^{\prime} 16.05^{\prime \prime S}$ & $35^{\circ} 52^{\prime} 30.81^{\prime \prime O}$ & 354 \\
\hline 3 & & 3 & Alto Branco & $7^{\circ} 12^{\prime} 26.50^{\prime \prime S}$ & $35^{\circ} 52^{\prime} 52.18^{\prime \prime O}$ & 678 \\
\hline 4 & & 18 & Jardim Tavares & $7^{\circ} 12^{\prime} 17.06^{\prime \prime S}$ & $35^{\circ} 52^{\prime} 11.96^{\prime \prime O}$ & 1.148 \\
\hline 5 & & 19 & Jardim Tavares & $7^{\circ} 12^{\prime} 31.27^{\prime \prime S}$ & $35^{\circ} 52^{\prime} 14.49^{\prime \prime O}$ & 3.309 \\
\hline 6 & & 20 & Jardim Tavares & $7^{\circ} 12^{\prime} 12.80^{\prime \prime S}$ & $35^{\circ} 52^{\prime} 13.38^{\prime \prime O}$ & 10.592 \\
\hline 7 & & 21 & Jardim Tavares & $7^{\circ} 12^{\prime} 28.49^{\prime \prime S}$ & $35^{\circ} 52^{\prime} 5.55^{\prime \prime O}$ & 7.877 \\
\hline 8 & & 22 & Jardim Tavares & $7^{\circ} 12^{\prime} 54.24^{\prime \prime S}$ & $35^{\circ} 52^{\prime} 33.46^{\prime \prime O}$ & 318 \\
\hline 9 & & 30 & Palmeira & $7^{\circ} 12^{\prime} 20.00^{\prime \prime S}$ & $35^{\circ} 53^{\prime} 39.84^{\prime \prime O}$ & 4.943 \\
\hline & & & & & ¿Área & 30.103 \\
\hline 10 & \multirow{4}{*}{ Zona Leste } & 7 & Castelo Branco & $7^{\circ} 12^{\prime} 55.16^{\prime \prime S}$ & $35^{\circ} 52^{\prime} 2.61^{\prime \prime O}$ & 3.739 \\
\hline 11 & & 23 & José Pinheiro & $7^{\circ} 13^{\prime} 47.39^{\prime \prime S}$ & $35^{\circ} 52^{\prime} 3.64^{\prime \prime} \mathrm{O}$ & 2.900 \\
\hline 12 & & 26 & Mirante & $7^{\circ} 14^{\prime} 0.54^{\prime \prime S}$ & $35^{\circ} 51^{\prime} 45.48^{\prime \prime O}$ & 1.596 \\
\hline 13 & & 27 & Monte Castelo & $7^{\circ} 13^{\prime} 35.54^{\prime \prime S}$ & $35^{\circ} 51^{\prime} 57.51^{\prime \prime O}$ & 23.547 \\
\hline & & & & & ¿Área & 31.782 \\
\hline 14 & \multirow{13}{*}{ Zona Sul } & 8 & Catolé & $7^{\circ} 13^{\prime} 53.38^{\prime \prime S}$ & $35^{\circ} 53^{\prime} 2.57^{\prime \prime O}$ & 2.943 \\
\hline 15 & & 9 & Catolé & $7^{\circ} 14^{\prime} 35.71 " \mathrm{~S}$ & $35^{\circ} 53^{\prime} 10.11^{\prime \prime O}$ & 1.292 \\
\hline 16 & & 10 & Cruzeiro & $7^{\circ} 14^{\prime} 26.42^{\prime \prime S}$ & $35^{\circ} 54^{\prime} 18.00^{\prime \prime} \mathrm{O}$ & 23.501 \\
\hline 17 & & 13 & Distrito Industrial & $7^{\circ} 15^{\prime} 51.52^{\prime \prime S}$ & $35^{\circ} 53^{\prime} 43.54^{\prime \prime} \mathrm{O}$ & 1.796 \\
\hline 18 & & 14 & Distrito Industrial & $7^{\circ} 15^{\prime} 48.30^{\prime \prime S}$ & $35^{\circ} 53^{\prime} 33.47^{\prime \prime} \mathrm{O}$ & 3.744 \\
\hline 19 & & 15 & Distrito Industrial & $7^{\circ} 15^{\prime} 28.10^{\prime \prime S}$ & $35^{\circ} 53^{\prime} 9.30^{\prime \prime O}$ & 2.331 \\
\hline 20 & & 16 & Itararé & $7^{\circ} 15^{\prime} 23.28^{\prime \prime S}$ & $35^{\circ} 52^{\prime} 54.94^{\prime \prime O}$ & 2.241 \\
\hline 21 & & 17 & Jardim Paulistano & $7^{\circ} 15^{\prime} 7.53^{\prime \prime S}$ & $35^{\circ} 53^{\prime} 51.96 " \mathrm{O}$ & 2.175 \\
\hline 22 & & 24 & Liberdade & $7^{\circ} 14^{\prime} 25.85^{\prime \prime S}$ & $35^{\circ} 53^{\prime} 24.49^{\prime \prime O}$ & 613 \\
\hline 23 & & 37 & Tambor & $7^{\circ} 14^{\prime} 41.08^{\prime \prime S}$ & $35^{\circ} 53^{\prime} 16.86^{\prime \prime O}$ & 16.997 \\
\hline 24 & & 38 & Tambor & $7^{\circ} 15^{\prime} 16.67 " \mathrm{~S}$ & $35^{\circ} 53^{\prime} 29.07^{\prime \prime O}$ & 5.464 \\
\hline 25 & & 44 & Vila Cabral & $7^{\circ} 14^{\prime} 49.49^{\prime \prime S}$ & $35^{\circ} 52^{\prime} 16.46^{\prime \prime O}$ & 4.035 \\
\hline 26 & & 45 & Vila Cabral & $7^{\circ} 14^{\prime} 30.86^{\prime \prime S}$ & $35^{\circ} 52^{\prime} 2.44^{\prime \prime O}$ & 6.021 \\
\hline & & & & & ¿Área & 73.153 \\
\hline 27 & \multirow{10}{*}{ Zona Oeste } & 4 & Bela Vista & $7^{\circ} 13^{\prime} 22.83^{\prime \prime S}$ & $35^{\circ} 54^{\prime} 4.43^{\prime \prime} 0$ & 41.467 \\
\hline 28 & & 5 & Bela Vista & $7^{\circ} 13^{\prime} 14.05^{\prime \prime S}$ & $35^{\circ} 54^{\prime} 16.65^{\prime \prime O}$ & 1.970 \\
\hline 29 & & 6 & Bodocongó & $7^{\circ} 12^{\prime} 36.66^{\prime \prime S}$ & $35^{\circ} 55^{\prime} 29.29^{\prime \prime O}$ & 936 \\
\hline 30 & & 11 & Dinamérica & $7^{\circ} 14^{\prime} 27.88^{\prime \prime S}$ & $35^{\circ} 54^{\prime} 50.19^{\prime \prime} \mathrm{O}$ & 340 \\
\hline 31 & & 12 & Dinamérica & $7^{\circ} 14^{\prime} 26.56 " S$ & $35^{\circ} 55^{\prime} 7.74^{\prime \prime O}$ & 422 \\
\hline 32 & & 25 & Malvinas & $7^{\circ} 14^{\prime} 46.45^{\prime \prime S}$ & $35^{\circ} 55^{\prime} 9.23^{\prime \prime} \mathrm{O}$ & 593 \\
\hline 33 & & 28 & Monte Santo & $7^{\circ} 12^{\prime} 52.86^{\prime \prime S}$ & $35^{\circ} 53^{\prime} 56.19^{\prime \prime} \mathrm{O}$ & 718 \\
\hline 34 & & 29 & Monte Santo & $7^{\circ} 12^{\prime} 46.79^{\prime \prime S}$ & $35^{\circ} 54^{\prime} 18.42^{\prime \prime} \mathrm{O}$ & 4.948 \\
\hline 35 & & 31 & Ramadinha & $7^{\circ} 13^{\prime} 2.72^{\prime \prime S}$ & $35^{\circ} 55^{\prime} 41.61^{\prime \prime O}$ & 571 \\
\hline 36 & & 32 & Ramadinha & $7^{\circ} 13^{\prime} 1.89^{\prime \prime S}$ & $35^{\circ} 55^{\prime} 45.78^{\prime \prime} \mathrm{O}$ & 1.299 \\
\hline
\end{tabular}


Tabela 1 - Continuação...

\begin{tabular}{|c|c|c|c|c|c|c|}
\hline $\mathrm{N}^{\circ}$ & Zona da Cidade & Id. & Bairro & Latitude & Longitude & Área $\left(\mathrm{m}^{2}\right)$ \\
\hline 37 & \multirow{9}{*}{ Zona Oeste } & 33 & Santa Cruz & $7^{\circ} 14^{\prime} 31.91 " \mathrm{~S}$ & $35^{\circ} 54^{\prime} 35.10^{\prime \prime O}$ & 682 \\
\hline 38 & & 34 & Santa Cruz & $7^{\circ} 14^{\prime} 18.42 " \mathrm{~S}$ & $35^{\circ} 54^{\prime} 24.20^{\prime \prime O}$ & 4.131 \\
\hline 39 & & 35 & Santa Cruz & $7^{\circ} 14^{\prime} 45.45 " S$ & $35^{\circ} 54^{\prime} 55.67^{\prime \prime} 0$ & 627 \\
\hline 40 & & 36 & Santa Rosa & $7^{\circ} 14^{\prime} 17.34 " S$ & $35^{\circ} 54^{\prime} 17.42^{\prime \prime O}$ & 1.020 \\
\hline 41 & & 39 & Universitário & $7^{\circ} 12^{\prime} 28.16^{\prime \prime S}$ & $35^{\circ} 54^{\prime} 55.56^{\prime \prime O}$ & 1.005 \\
\hline 42 & & 40 & Universitário & $7^{\circ} 12^{\prime} 32.70 " \mathrm{~S}$ & $35^{\circ} 54^{\prime} 17.01 " \mathrm{O}$ & 3.192 \\
\hline 43 & & 41 & Universitário & $7^{\circ} 12^{\prime 2} 29.89^{\prime \prime S}$ & $35^{\circ} 54^{\prime} 14.66^{\prime \prime O}$ & 1.875 \\
\hline 44 & & 42 & Universitário & $7^{\circ} 12^{\prime 26.91 " S}$ & $35^{\circ} 54^{\prime} 12.38^{\prime \prime O}$ & 724 \\
\hline 45 & & 43 & Universitário & $7^{\circ} 12^{\prime} 37.21 " \mathrm{~S}$ & $35^{\circ} 54^{\prime} 36.65^{\prime \prime O}$ & 2.363 \\
\hline & & & & & $\sum$ Área & 68.883 \\
\hline
\end{tabular}

Fonte: Autor (2019)

Posteriormente à confirmação do local de descarte inadequado de RCC, foi traçado um polígono no Google Earth Pro delimitando a área aterrada atual do local onde estão sendo depositados os RCC e o seu georrefrenciamento, conforme exemplo nas Fig. 5 a 7.

Figura 5 - Delimitação do local de descarte de RCC (Bairro Bela Vista)

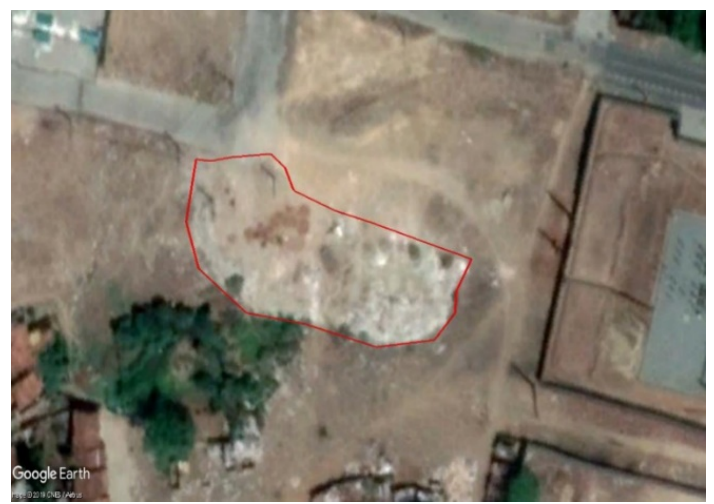

Fonte: Google Earth Pro (2019)

Figura 6 - Delimitação do local de descarte de RCC (Bairro Tambor)

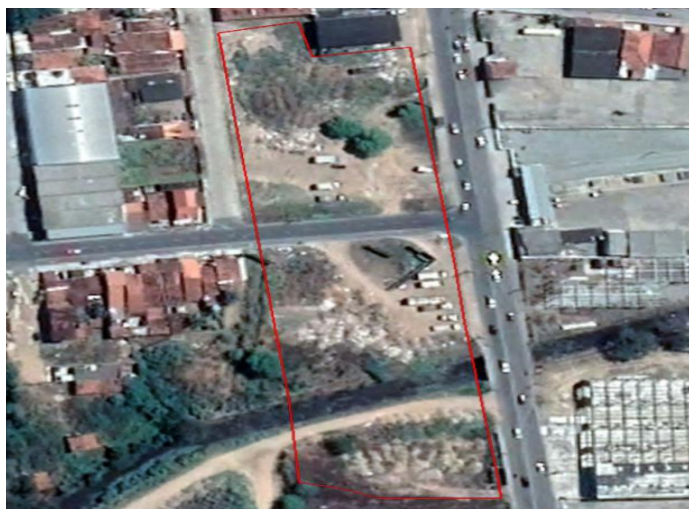

Fonte: Google Earth Pro (2019)
Figura 7 - Delimitação do local de descarte de RCC (Bairro Monte Castelo)

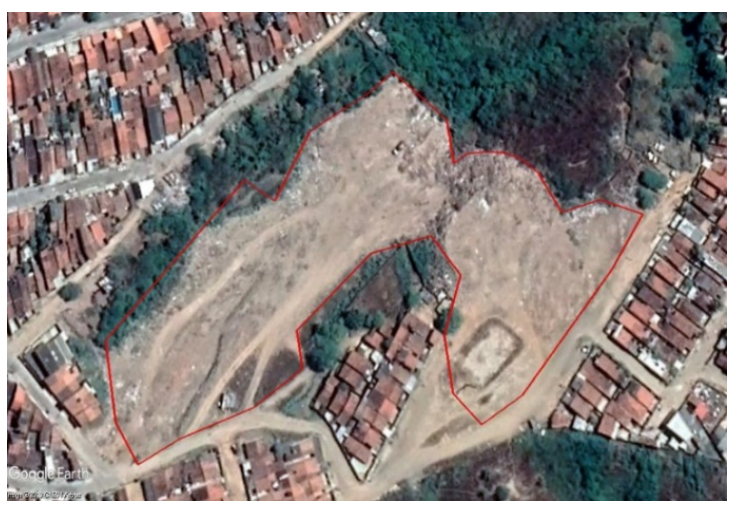

Fonte: Google Earth Pro (2019)

Cada local delimitado pelo polígono possui um valor de área que foi extraído e corresponde ao período de maio de 2018 a maio de 2019, portanto esses valores podem variar para mais ou para menos ao longo do tempo.

Ainda conforme a Tabela 1, os locais de descarte de RCC estão presentes em quatro das cinco zonas existentes na cidade de Campina Grande. A zona oeste e a sul são as regiões onde existe a maior quantidade de locais com descarte inadequado de RCC e, consequentemente, possuem o maior somatório de área. $\mathrm{Na}$ zona central da cidade não foi encontrada nenhuma área plausível de descarte de RCC.

Esse panorama é evidente com a espacialização das áreas delimitadas em polígonos no software livre Quantum Gis (QGis), conforme a Fig. 8. Essas áreas foram exportadas para o QGis e numeradas para melhor visualização. 
Figura 8 - Mapa das áreas de descarte de RCC



É possível visualizar na Fig. 8 a dispersão das áreas de descarte de RCC, porém em locais mais afastados, como por exemplo os bairros do Velame, Acácio Figueiredo, Cidades, Três Irmãs, Serrotão, Novo Bodocongó, Cuités, Jardim Continental e Nações, não possuem disposições de RCC. Isso ocorre, provavelmente, por falta de obras de construção civil que produzem grandes volumes de RCC e aos custos relacionados ao combustível para o transporte e descarte em locais mais afastados da zona central.

Devido à grande quantidade de imagens disponíveis na pesquisa, serão expostos apenas os locais de descarte inadequado de RCC mais representativos. Assim, conforme a Fig. 9, as áreas que possuem maior destaque estão localizadas nos bairros da Bela Vista $\left(41.467 \mathrm{~m}^{2}\right)$, Monte Castelo $\left(23.547 \mathrm{~m}^{2}\right)$, Cruzeiro (23.501 $\left.\mathrm{m}^{2}\right)$ e Tambor $\left(16.997 \mathrm{~m}^{2}\right)$. 
Figura 9 - Gráfico das áreas dos locais de descarte de RCC

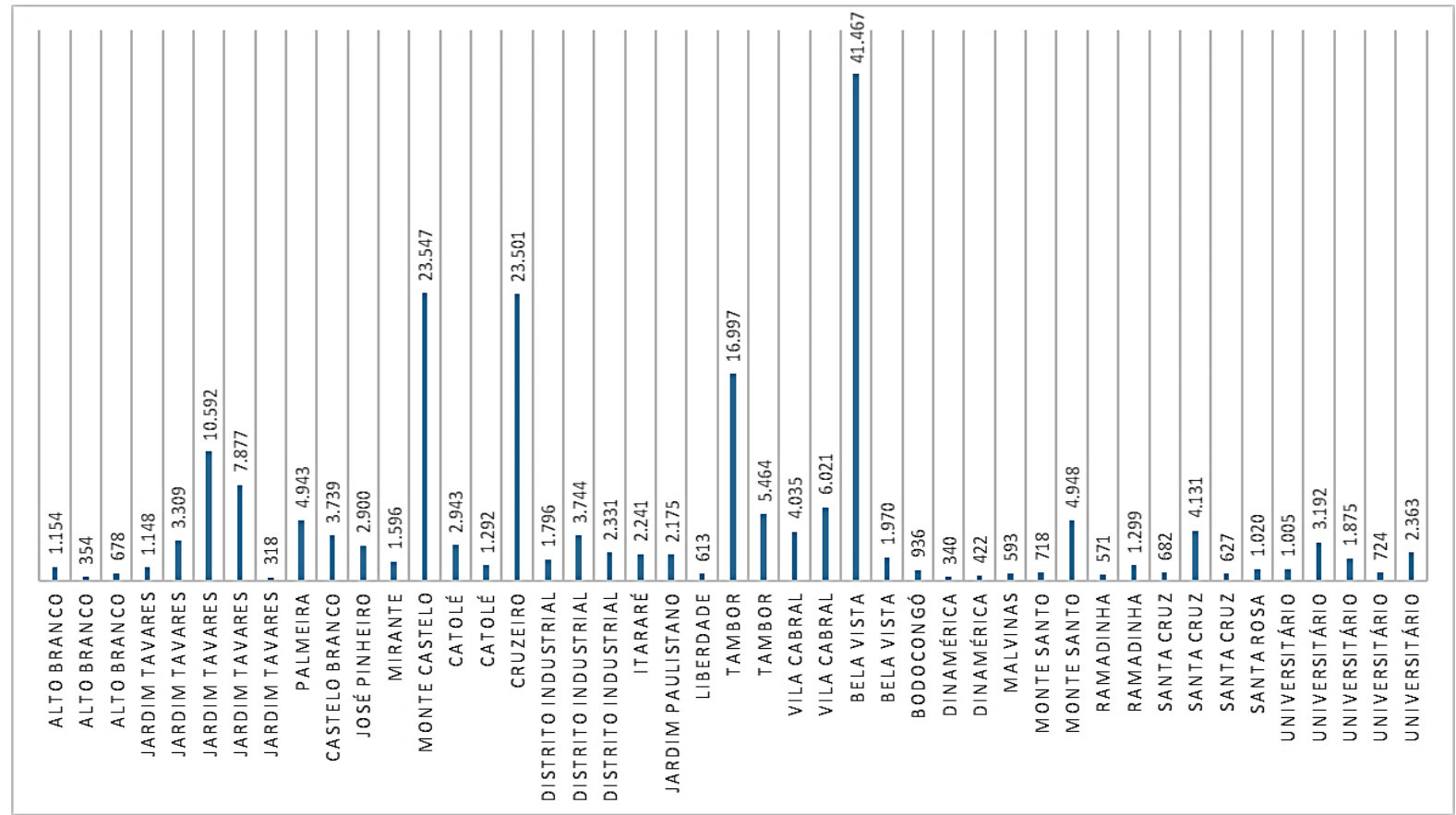

Fonte: Autor (2019)

A seguir, nas Fig. 10 a 13, são apresentados os locais fixos onde existe o constante descarte de RCC, bem como se faz a comparação entre pe- ríodos diferentes evidenciando as alterações do espaço físico no ambiente.

Figura 10 - Bairro Bela Vista

(A) setembro de 2017



(B) maio de 2019

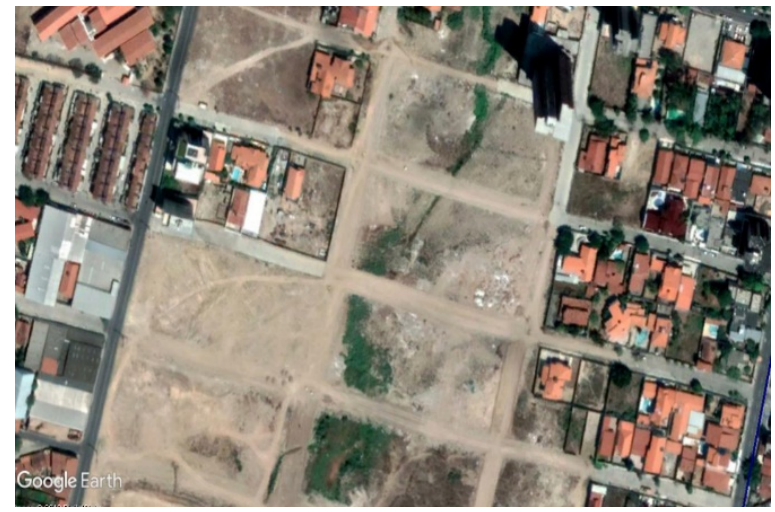

Fonte: Google Earth Pro (2019) 
Figura 11 - Bairro Cruzeiro

(A) dezembro de 2017

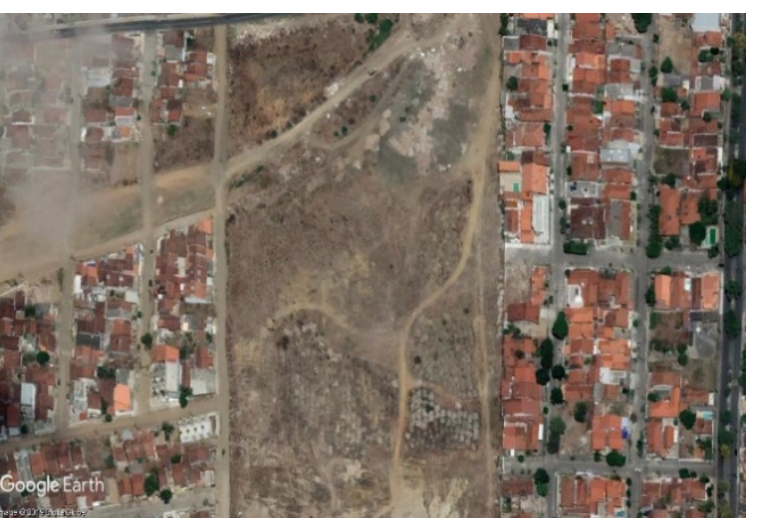

(B) maio de 2019



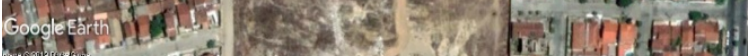

Fonte: Google Earth Pro (2019)

Figura 12 - Bairro Monte Castelo

(A) dezembro de 2017

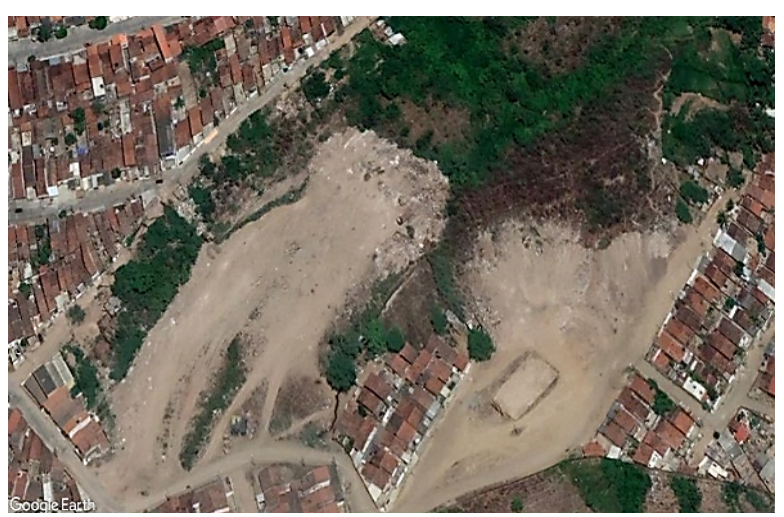

(B) maio de 2019

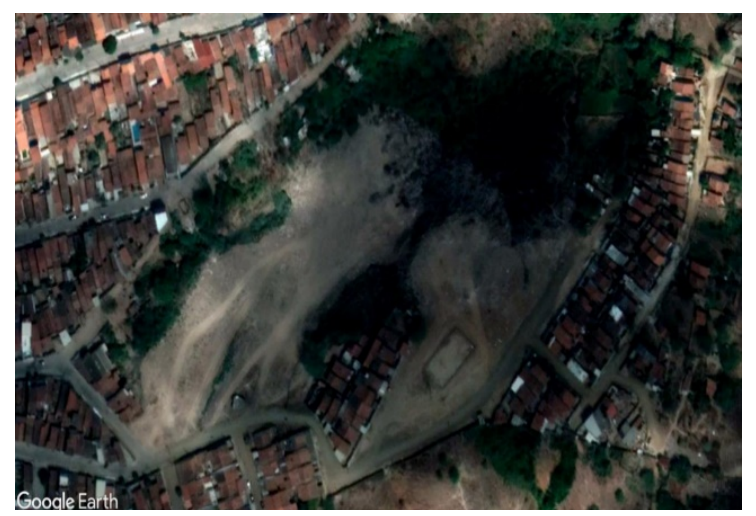

Fonte: Google Earth Pro (2019)

Figura 13 - Bairro Tambor

(A) agosto de 2017



Fonte: Google Earth Pro (2019)
(B) maio de 2019

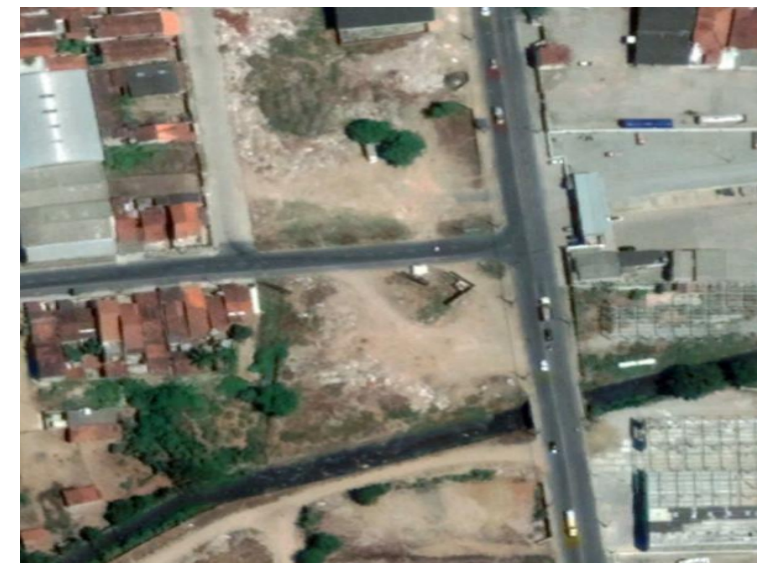

Pro (2019) 
$\mathrm{Na}$ verificação in loco nos locais de descarte inadequado de RCC, além da percepção visual em termos de volume, comprovou-se a predominância de resíduos Classe A e B, conforme Fig. 14 a 17. Os resíduos de classe $A$ são os recicláveis ou reutilizáveis como agregados e representam cerca de $90 \%$ do total de RCC, enquanto os de classe B são os resíduos recicláveis e reutilizáveis para outras finalidades.

Ao examinar o local, percebe-se que a maior parte dos resíduos é de Classe $A$, como concreto, tijolos, telhas, pré-moldado, areia, argamassa, materiais cerâmicos, blocos e azulejos, ou seja, são os resíduos que possuem elevado potencial de recuperação.
Logo após, em uma proporção bem menor, os resíduos de Classe $\mathrm{B}$, como gesso, madeira, vergalhão de ferro, latas de tintas vazias, papel, papelão, plástico e vidros, também são perceptíveis nos locais de descarte inadequado de RCC. Esses resíduos são classificados dessa forma por possuírem técnicas de recuperação específicas quando a sua destinação é realizada corretamente. Os resíduos de Classe $B$, apesar de terem volume bem inferior quando comparados com os de Classe $A$, possuem a característica de serem distinguidos facilmente nos locais onde existe um vasto aglomerado de RCC. Essa particularidade pode ser visualizada também nas Fig. 14 a 17.

Figura 14 - Visita no local de descarte de RCC (Bairro Bela Vista)

(A) janeiro de 2019



(B) janeiro de 2019

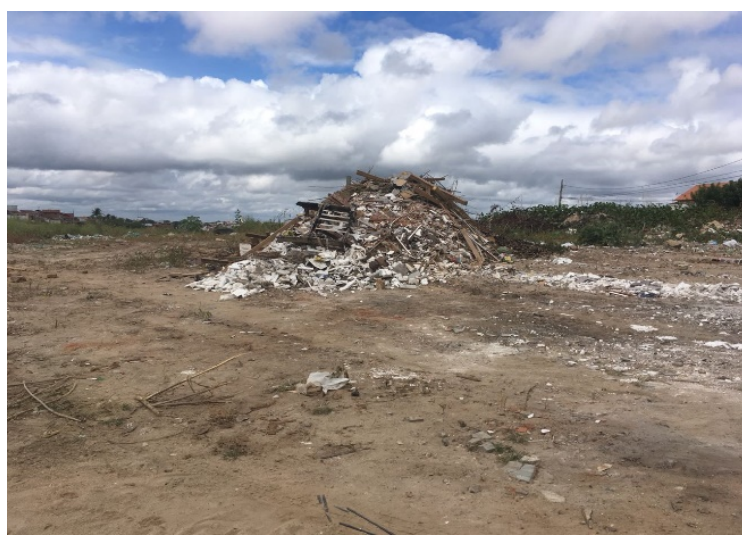

Fonte: Autor (2019)

Figura 15 - Visita no local de descarte de RCC (Bairro Cruzeiro)

(A) junho de 2018

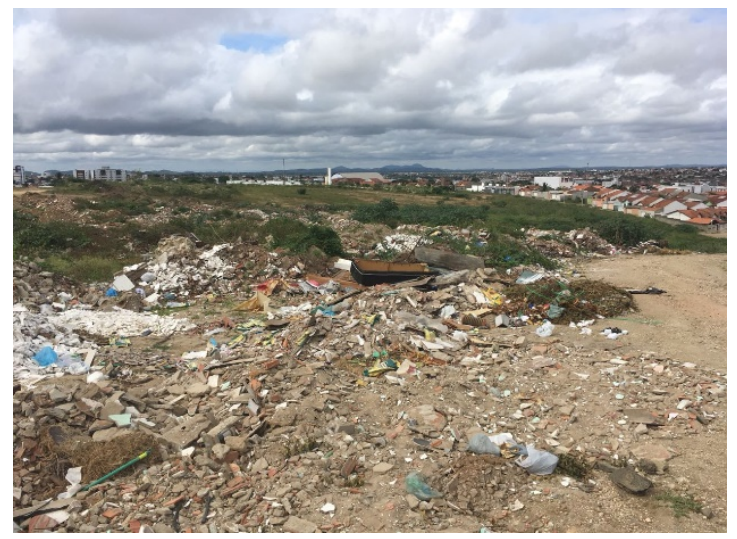

(B) junho de 2018

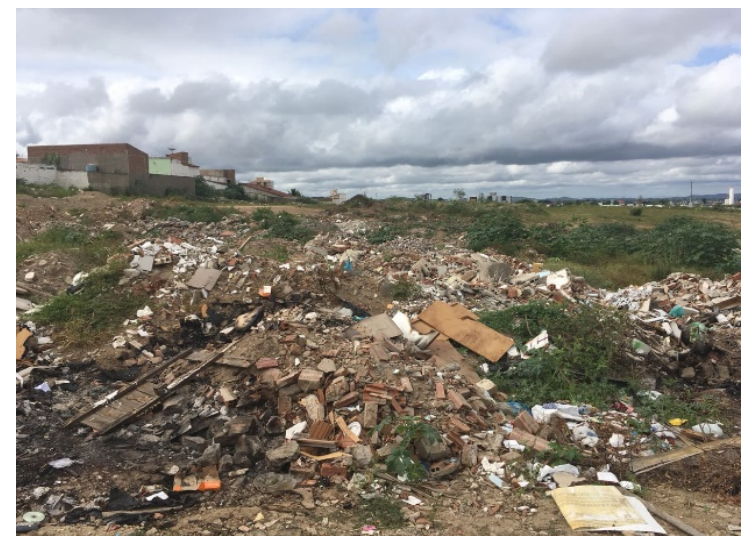

Fonte: Autor (2019) 
Figura 16 - Visita no local de descarte de RCC (Bairro Tambor)

(A) janeiro de 2019

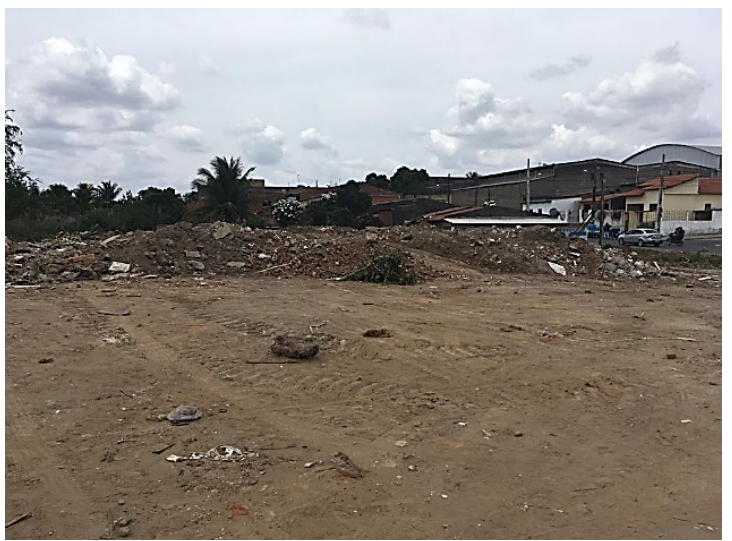

(B) janeiro de 2019

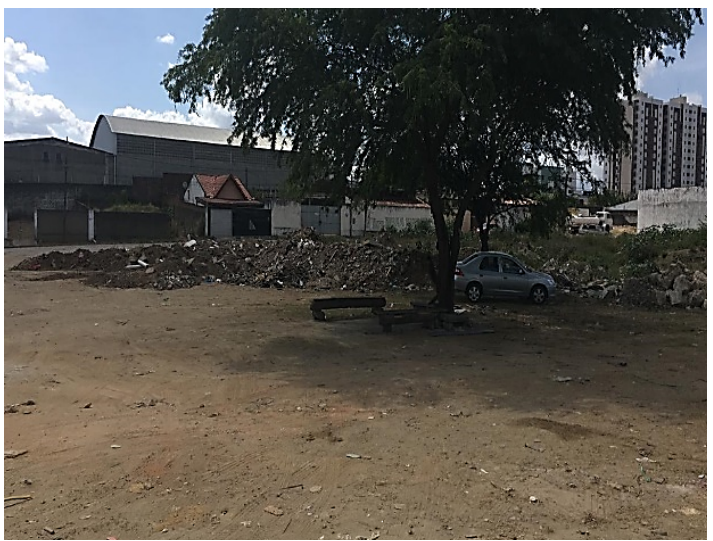

Fonte: Autor (2019)

Figura 17 - Visita no local de descarte de RCC (Bairro Monte Castelo)

(A) junho de 2018

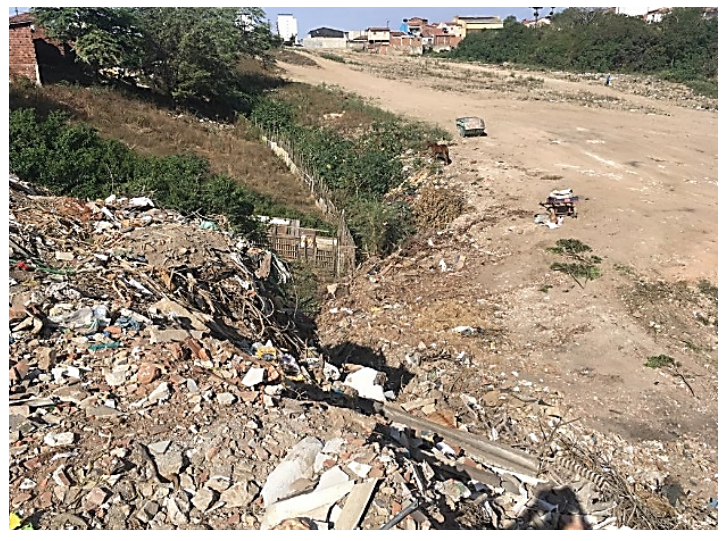

(B) junho de 2018

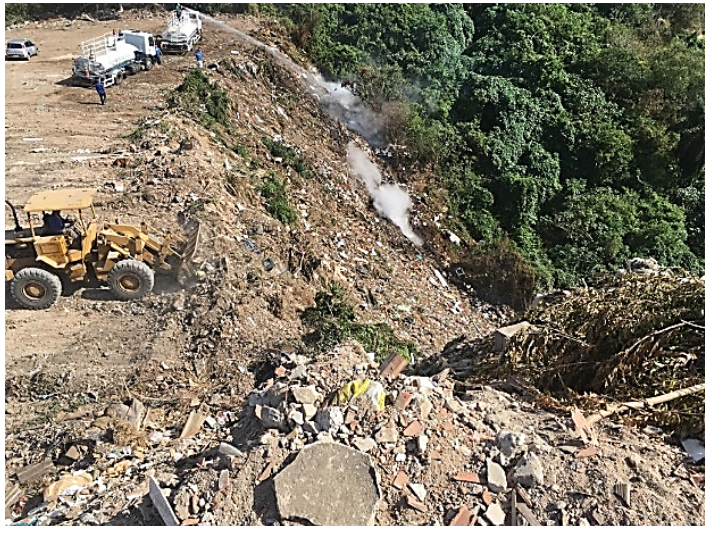

Fonte: Autor (2019)

Na Fig. 17, visualiza-se a drenagem natural obstruída, uma caçamba estacionária e uma carroça. As caçambas estacionárias e as carroças são constantemente utilizadas para a coleta do RCC na fonte geradora por empresas terceirizadas ou trabalhadores informais. Vale salientar que, embora a determinação seja colocar apenas RCC nas caçambas, é comum encontrar resíduo sólido urbano (RSU) no fundo delas.

É possível perceber também na figura a dimensão do volume de RCC descartado e aterrado sobre a vegetação sem a preparação do terreno, onde possivelmente será construído um conjun- to habitacional ou uma área de lazer. Olhando a imagem não é possível visualizar, porém durante a visita foi observada a presença de pneus, resto de móveis, RSU e latas de tinta. Outro ponto que chamou a atenção foi a presença do caminhão pipa no local para controlar os pequenos focos de incêndio na base do talude do aterro de RCC. A causa provável da ocorrência é interpretada como a presença de algum combustível inflamável, mas não se descarta a hipótese de a origem do fogo ser a existência do gás metano proveniente da decomposição da matéria orgânica disposta no local ou coberta pelo aterro. 
A maior parte dos resíduos produzidos na construção civil que envolvem o processo de construção, reforma e demolição são descartados em aterros sanitários ou terrenos baldios devido à ausência de mercados para suas formas recicladas. Esse material poderia servir de matériaprima para agregados de ótima qualidade, podendo ser utilizados de forma direta ou indireta nas atividades para a confecção de tijolos, blocos pré-moldados, meio-fio, calçadas, argamassa de revestimento, camadas de base e sub-base, pavimentos, entre outros (BRASILEIRO, 2015; DURAN, 2006).

No contexto nacional, existem poucos munícipios que gerenciam corretamente o RCC ou que possuam o plano diretor de resíduos da construção civil. Segundo a Pesquisa Nacional de Saneamento Básico realizada pelo Instituto Brasileiro de Geografia e Estatística (IBGE, 2008), 4.031 municípios $(72,45 \%)$ possuem "serviço de manejo dos resíduos de construção e demolição"; em 392 municípios (7,05\%) tem "existência e algum tipo de processamento dos resíduos", em $124(2,23 \%)$ existe a "triagem simples dos resíduos de construção e demolição reaproveitáveis (classes A e B)", em 14 (0,25\%) existe "triagem e trituração simples dos resíduos classe A", em 20 $(0,36 \%)$ existe "triagem e trituração dos resíduos classe $A$, com classificação granulométrica dos agregados reciclados" e apenas em 79 municípios $(1,42 \%)$ existe o programa de "reaproveitamento dos agregados produzidos na fabricação de componentes construtivos".

Países como a Holanda e Coreia do Sul alcançaram 98\% de recuperação de RCC (ETC/SCP, 2009; YANG et al., 2015) por meio da proibição do descarte de RCC com alto potencial de recuperação, obrigação da triagem na origem, criação de um mercado de produtos reciclados e multas elevadas pelo descarte inadequado. Outra questão importante foi o investimento em publicidade, sessões de esclarecimento, incentivos fiscais e fi- nanceiros para que a segregação fosse realizada na fonte. Essas políticas garantiram o processo mais rápido, eficaz e menos dispendioso (MINISTRY OF HOUSING, SPATIAL PLANNING AND THE ENVIRONMENT, 2001, apud MÁLIA et al., 2013)

\section{CONCLUSÃO}

A disseminação de disposições de RCC pela área urbana do município de Campina Grande modifica as condições de saneamento ambiental da cidade bem como as condições sociais. Esse problema é resultado de uma gestão ineficiente, ausência de mercado para as suas formas recicladas, falta de fiscalização e de conscientização da população e das empresas geradoras.

Os locais de descarte inadequado de RCC possuem diversas áreas geométricas que variam de tamanho com o tempo. Pequenas áreas podem possuir características de sazonalidade, ou seja, em determinados períodos ou com o passar dos anos, podem deixar de existir. Entretanto, as grandes áreas permanecem ativas e, dependendo do local, continuam crescendo em volume e ampliando-se em área.

Por se tratar de resíduos com alto potencial de recuperação, cabe às empresas promover técnicas para o reúso do RCC, principalmente os de Classe A, na origem. Uma das formas de alcançar esse objetivo é por meio de parcerias com Universidades e Institutos de Pesquisas visando propor soluções para a reutilização in natura ou como agregado em processos construtivos

O constante descarte de RCC nesses locais tem prejudicado principalmente as linhas de drenagem natural e o escoamento das águas pluviais. Por se tratar de um resíduo descartado na zona urbana, os moradores das regiões circunvizinhas às disposições de RCC acabam descartando também RSU, potencializando a presença de vetores e pequenos lixões na cidade. Em alguns locais, devido à presen- 
ça de RSU ou de algum combustível inflamável, foi identificada presença de fogo. Esse problema serve de base para alertar o poder público sobre a periculosidade desses locais, visando políticas públicas voltadas para uma melhor ocupação do espaço urbano, minimizando os riscos para a vizinhança.

Outro fato observado foi a vegetação se desenvolvendo nas áreas onde existe a presença de resíduo, cobrindo os RCC e camuflando a presença deles nos locais de descarte inadequado. Essa situação pode ser utilizada como objeto de estudos acadêmicos sobre a característica da flora nesses locais, bem como, se o vigor vegetativo durante o crescimento da vegetação é influenciado pela presença de resíduos Classe A e B.

Portanto, é importante difundir pesquisas para que a construção civil agregue valor aos resíduos, visando reutilizá-los na cadeia produtiva ou obter vantagens financeiras com os seus subprodutos, bem como o poder público seguir o exemplo de países que alcançaram elevado percentual de recuperação de RCC.

Assim, busca-se atender ao princípio da responsabilidade compartilhada disposto na Lei 12.305/2010 e o artigo 225 da Constituição Federal (BRASIL, 1988), que diz: "Todos têm direito ao meio ambiente ecologicamente equilibrado, bem de uso comum do povo e essencial à sadia qualidade de vida, impondo-se ao poder público e à coletividade o dever de defendê-lo e preservá-lo para as presentes e futuras gerações."

\section{AGRADECIMENTO}

O autor agradece à Coordenação de Aperfeiçoamento de Pessoal de Nível Superior (Capes) pela concessão de bolsa de mestrado.

\section{CONTRIBUIÇÃO DOS AUTORES}

Todos os autores contribuíram de forma igualitária.

\section{REFERÊNCIAS}

ABRECON - Associação Brasileira para Reciclagem de Resíduos da Construção Civil e Demolição (2015) Mercado. Disponível em: <https://abrecon.org.br/entulho/mercado/>. Acesso em: 04/09/2019.

ABRELPE (2017). Panorama dos Resíduos Sólidos no Brasil 2017. Disponível em: http://www.abrelpe.org.br/Panorama/panorama2017.pdf. Acesso em: 22 de janeiro de 2019.

BRASIL, Constituição Federal. Constituição federal. São Paulo: Revista dos Tribunais, 1988.

BRASIL. 2002. Ministério do meio ambiente. Resolução CONAMA $N^{\circ} 307$, de 05 de julho de 2002. Estabelece diretrizes, critérios e procedimentos para a gestão dos resíduos da construção civil. Diário Oficial da União, Brasília. 17 de julho de 2002.

BRASILEIRO, L. L.; MATOS, J. M. E. Revisão bibliográfica: reutilização de resíduos da construção e demolição na indústria da construção civil (Literature review: reuse of construction and demolition waste in the construction industry). Cerâmica, v. 61, p. 178-189, 2015. http://dx.doi.org/10.1590/036669132015613581860

CONTRERAS, M. et al. Recycling of construction and demolition waste for producing new construction material (Brazil case-study). Construction and Building Materials, v. 123, p. 594-600, 2016. http://dx.doi.org/10.1016/j.conbuildmat.2016.07.044

DURAN, X.; LENIHAN, H.; O'REGAN, B. A model for assessing the economic viability of construction and demolition waste recycling - the case of Ireland. Resources, Conservation and Recycling, v. 46, n. 3, p. 302-320, 2006. https://doi.org/10.1016/j. resconrec.2005.08.003

ETC/SCP (2009). Europe as a Recycling Society- Present recycling levels of Municipal Waste and Construction \& Demolition Waste in the EU. Prepared by Christian Fischer and Mads Werge, ETC/SCP working paper 2/2009. European Topic Centre on Resource and Waste Management. Disponível em: http:/scp.eionet.Europa.eu/publications/wp2009_2. Acesso em 20/02/2019.

FAVARETTO, P. et al. Characterization and use of construction and demolition waste from south of Brazil in the production of foamed concrete blocks. Applied Sciences, v. 7, n. 10, p. 1090, 2017. https://doi.org/10.3390/app7101090

HALMEMAN, M. C. R.; DE SOUZA, P. C.; CASARIN, A. N. Caracterização dos resíduos de construção e demolição na unidade de recebimento de resíduos sólidos no município de Campo Mourão-PR. Revista Tecnológica, p. 203-209, 2010. https://doi. org/10.4025/revtecnol.v0i0.8821

IBGE, Instituto Brasileiro de Geografia e Estatística. Cidades. 2017. Disponível em: <http://cidades.ibge.gov.br/xtras/uf. php?lang=\&coduf=25\&search=paraiba $>$. Acesso: junho de 2018. 
IBGE, Instituto Brasileiro de Geografia e Estatística. Banco de dados Agregados, Censo 2008, disponível em https://biblioteca. ibge.gov.br/visualizacao/livros/liv45351.pdf, acesso 14/02/2019.

KLEIN, F. B.; DIAS, S. L. F. G. A deposição irregular de resíduos da construção civil no município de São Paulo: um estudo a partir dos instrumentos de políticas públicas ambientais. Desenvolvimento e Meio Ambiente, v. 40, 2017. http://dx.doi.org/10.5380/ dma.v40i0.47703

MÁLIA, M. Indicadores de resíduos de construção e demolição. Lisboa. Dissertação (Mestrado em Engenharia Civil), Instituto Superior Técnico, Lisboa/Portugal, 2010.
BRASIL, Ministério do Meio Ambiente - MMA, Projeto internacional de cooperação técnica para a melhoria da gestão ambiental urbana no Brasil - BRA/OEA/08/001 (2010) 320p.

PRODANOFF, J. H. A. Avaliação da poluição difusa gerada por enxurradas em meio urbano. Rio de Janeiro, 2005.

Yang, W.-S., Park, J.-K., Park, S.-W., Seo, Y.-C. Past, present and future of waste management in Korea. J. Mater. Cycles Waste Manag. n. 17, p. 207-217, 2015 . https://doi.org/10.1007/ s10163-014-0301-7 